\title{
Transport of Cytoskeletal Elements from Parent Axons into Regenerating Daughter Axons
}

\author{
Irvine G. McQuarrie ${ }^{1,2,4}$ and Raymond J. Lasek ${ }^{3}$ \\ 1Division of Neurosurgery, 2Department of Developmental Genetics and Anatomy, and BBioarchitectonics Center, Case \\ Western Reserve Univcrsity School of Medicine, and ${ }^{4}$ Medical Research Service, Veterans Administration Medical Center, \\ Cleveland, Ohio 44106
}

\begin{abstract}
The kinetics of slow axonal transport in newly regenerating axonal sprouts were compared with those in nonelongating axons. The slowly transported cytoskeletal proteins of ventral motor axons were prelabeled by microinjection of ${ }^{35} \mathrm{~S}$ methionine into the spinal cord. Pulse-labeled slow transport "waves" were observed as they progressed from the surviving "parent" axon stumps (located proximal to a crush lesion) into regenerating "daughter" axon sprouts (located distal to the lesion). Prelabeled cytoskeletal elements of the parent axons were transported into daughter axons, to become distributed into 2 transport waves, "a" and "b." The rate and composition of these waves corresponded to the slow transport subcomponents, $\mathrm{SCa}$ and $\mathrm{SCb}$. The shapes of the " $a$ " and " $b$ " waves suggested that the cytoskeletal elements had been reorganized at the junction between the parent and daughter axons. This hypothesis was supported by quantitative analyses of the transport distribution for individual radiolabeled cytoskeletal proteins (actin, spectrin, a 58-67 kDa group that includes microtubule-associated proteins, calmodulin, and tubulin). Specifically, during the first week of outgrowth, the amounts of radiolabeled calmodulin and 58-67 kDa proteins were greater in daughter axons than in nonregenerating control axons. These results support Paul Weiss's "conservative" model of axonal regeneration, which holds that the preexisting transported cytoskeletal elements that continually maintain axonal structure can also provide the cytoskeletal elements required for axonal regeneration. In addition, the results elucidate some of the reorganizational changes in cytoskeletal elements that occur when these are recruited from the parent axon to form daughter axons.
\end{abstract}

When an axon in the peripheral nervous system is cut, a growth cone is generated near the cut end of the "parent" axon and a new "daughter" axon is extended. If the conditions of the surrounding substrate facilitate growth of the daughter axon, the rate of elongation is largely determined by slow axonal transport

Received Nov. 17, 1987; revised June 27, 1988; accepted July 18, 1988

This work was supported by grants to I.G.M. from Paralyzed Veterans of America (OVR-095), Veterans Administration, and USPHS (NS-18975), and a grant to R.J.L. from USPHS (NS-15731). We wish to thank Martha King, Vivian Pocek, Magda Hadady, Nicholas Ponlos, Shirley Ricketts, and Diane Filsinger for technical assistance, and Margaret Smith, Gloria McClain, Sylvia Kertesy, and Marguarita Schmid for illustrations.

Correspondence should be addressed to Dr. Irvine G. McQuarrie, Division of Neurosurgery, Case Western Reserve University, Cleveland, OH 44106.

Copyright (C) 1989 Society for Neuroscience $0270-6474 / 89 / 020436-1$ 1 $\$ 02.00 / 0$ mechanisms. These arc cstablished by the cytoskeletal polymers present in the axon when it is cut. The rate of outgrowth is a function of the rate of the $\mathrm{SCh}$ subcomponent of slow axonal transport, a relationship that holds for many different kinds of axons with different rates of SCb (Lasek et al., 1981; McQuarrie and Grafstein, 1982; McQuarrie, 1983, 1984; Wujek and Lasek, 1983). Furthermore, if either the rate of SCb or the amount of protcin it carrics increases because of a prior "conditioning" axotomy, then the rate of axonal elongation increases accordingly (McQuarrie, 1983, 1984, 1986a, b, 1988).

On the basis of these observations and others (Lasek and Hoffman, 1976; Hoffman and Lasek, 1975; Lasek et al., 1983, 1984; Tashiro et al., 1984; Lasek, 1986, George et al. 1988), the following model has been proposed for the extension of the parent axon cytoskeleton into daughter axons (Lasek et al., 1983; McQuarrie, 1983, 1985). The preexisting cytoskeletal elements of the parent axon continuc to be transportcd into the parent axon stump. Microfilaments and other cytomatrix components carried by $\mathrm{SCb}$ contribute to the development of growth cones. Some of the microtubules in transit are presumably transported into these sprouts instead of being added to the mass of microtubules that accumulate in the axon stump (Friede and Bischhausen, 1980). As the daughter axon elongates, these microtubules provide a substrate for other axonally transported materials. For example, anterogradely transported tubulovesicular elements are specifically transported along microtubules and will tend to follow the new microtubule paths that are established at the junction between parent and daughter axons (Miller et al., 1987). The microtubules that bridge the parent-daughter junction (PDJ) may also direct cytoskeletal elements from the parent axon into the daughter axon. As more cytoskeletal elements are recruited, the cross-sectional area of the daughter axon would increase accordingly - to eventually equal that of the parent axon.

In the "conservative" model of axonal regeneration, originally set forth by Weiss and Hiscoe (1948), the daughter axon behaves essentially as a terminal branch of the parent axon. Many of the same cell motility mechanisms that normally provide for the renewal and maintenance of the intact axon continue to opcrate and thereby generate the "new" cytoskeleton of the daughter axon (Weiss, 1955). In the contemporary version of this model, the regenerated cytoskeleton is formed by the continued motility of cytoskeletal elements from the parent axon into and through the daughter axon (Lasek and Hoffman, 1976; Hoffman and Lasek, 1980).

The conservative model predicts that many of the same mech- 
anisms of translocation in an intact axon also operate in an elongating axon. To test this prediction, we have devised a new method for analyzing the kinetics and composition of prelabeled cytoskeletal elements that are transported from the parent axon into its daughter axons and have compared the results of these analyses with those obtained in nonelongating control axons. In our experiments, the slowly transported proteins in the axons of motor neurons were labeled by injection of radiolabeled amino acids into the spinal cord. The slowly transported waves of pulse-labeled cytoskeletal proteins were allowed to advance to the nerve crush site, arriving in time to advance from the parent axon into its newly formed daughter axons.

To follow the prelabeled, slowly transported cytoskelctal pro= teins into daughter axons, the motor axons are transected by crushing the sciatic nerve in the region of the front of the $\mathrm{SCb}$ wave. After the daughter axons have regenerated for some distance, the animals are killed and transport profiles of specific cytoskeletal and cytomatrix proteins are determined by SDSPAGE and quantitative analysis. These transport profiles are compared with those from comparable regions of normal axons. In this way, we can examine the transport of cytoskclctal clements from the cut parent axon into its daughter axon and compare that with transport in nonelongating control axons (McQuarric et al., 1986). Some of the observations in the present study have been previously reported in short abstracts accompanying brief presentations (McQuarrie et al., 1981; McQuarric, 1986a).

\section{Materials and Methods}

Motor neurons are chosen for labeling, instead of sensory neurons of the dorsal root ganglia, because (1) the axons are longer, (2) there are only 2 types of motor neurons-alpha and gamma-as opposed to a variety of size and functional types of sensory neurons, (3) only a single motor neuron type regenerates effectively - the alpha motor neuron (Brown and Butler, 1976; Takano, 1976), and (4) the growth cones of these remain close together in the distal nerve during the elongation phase of regeneration, whereas those of sensory axons are dispersed throughout the distal nerve (Bisby, 1979). Thus, even though a population of neurons is labeled, the population is sufficiently homogeneous in its response to axotomy to reflect the behavior of a typical alpha motor neuron.

Male Sprague-Dawley rats (Zivic-Miller) weighing 125-230 gm were anesthetized with i.p. Chloropent (sodium pentobarbital and chloral hydrate, Fort Dodge Laboratories) for removal of the T-12, T-13, and $\mathrm{L}-1$ laminae to expose the spinal cord. Five injections of $0.1-0.2 \mathrm{mCi}$ of $\mathrm{L}^{-35} \mathrm{~S}-$-methionine (specific activity of $0.5-1.0 \mathrm{mCi} / \mathrm{mm}$, New England Nuclear) were made in a parasagittal row into the right motor column of spinal cord segments L-3 through L-6, as previously described (McQuarrie, 1978; McQuarrie et al., 1986). One week later, rats were reanesthetized to crush the right L-4 spinal nerve near the confluence of the L-4 and L-5 spinal nerves $27-30 \mathrm{~mm}$ from the spinal cord (Fig. 1). The L-5 spinal nerve was excised, as were communications from the L-3 spinal nerve entering below the crush; the L6 root and spinal nerve were removed by applying traction to the spinal nerve. The crush lcsion consisted of two $10 \mathrm{sec}$ applications of a \#5B jeweler's forceps to full closure, a procedure that reliably axotomizes all nerve fibers (McQuarrie et al., 1977; McQuarrie, 1981, 1985). In a control group, regeneration was reliably prevented by excising the L4 spinal nerve (leaving a gap of $10 \mathrm{~mm}$ or more) in addition to excising the L5 spinal nerve and other contributions from the lumbosacral plexus to the sciatic nerve as above (McQuarrie and Grafstein, 1973). Rats were decapitated under the same anesthesic 7-16 d after nerve crush (14-23 d after isotope injection).

The L-4 ventral spinal root, L-4 spinal nerve, and contiguous sciatic nerve and branches were removed, straightened onto a piece of index card, and frozen-after marking the positions of the crush and the terminations of motor branches. Small segments of spinal cord were retained at the rostral extent of the L-4 ventral root. The frozen nerves were subsequently removed from index cards, kept frozen in $5 \%$ sucrose under dry ice, and sectioned into consecutive $3 \mathrm{~mm}$ segments on a Mickle gel slicer (Brinkmann Instrument Co.).

Nerve scgments were homogenized (glass-to-glass) in $0.25 \mathrm{ml}$ of SUB: $0.5 \%$ SDS, $8 \mathrm{~m}$ urea, and $2 \%$ beta-mercaptoethanol. Homogenates were centrifuged at $20,000 \times g$ for $15 \mathrm{~min}$ at $20-22^{\circ} \mathrm{C}$. Pellets were solubilized in $0.25 \mathrm{ml}$ BUST ( $2 \%$ beta-mercaptoethanol, $8 \mathrm{~m}$ urca, $1 \% \mathrm{SDS}$, and 0.2 м Tris, pH 7.3). Formula 963 scintillation cocktail ( $5 \mathrm{ml}$, New England Nuclear) was added and radioactivity measured in a liquid scintillation spectrometer (Beckman). A $10 \%$ aliquot of the supernatant was similarly counted; over $95 \%$ of the radioactivity in the homogenate was recovered in the supernatant. A $20-40 \%$ aliquot of the supernatant was subjected to SDS-PAGE at constant power $(10 \mathrm{~W})$, using $150 \times$ $150 \mathrm{~mm}$ gel chambers, $4 \%$ stacking gels, and $4-17.5 \%$ gradient gels (Lacmmli, 1970; McQuarric et al., 1986). After electrophoresis, gels were stained $(0.1 \%$ Coomassie brilliant blue in $35 \%$ methanol and $7 \%$ acetic acid), destained for photography, dehydrated with DMSO, impregnated with a fluor $(2,5$-diphenyloxazole/DMSO), rehydrated, vacuum-dried between dialysis membranes, and incubated at $-70^{\circ} \mathrm{C}$ under XAR-5 Kodak film (Laskey and Mills, 1975; McQuarrie et al., 1986).

Fluorograms were used as templates to remove gel regions that are known to largely contain the neurofilament triplet, tubulins, microtubule-associated proteins (MAPs) at $58-67 \mathrm{kDa}$, actin, spectrin, and calmodulin (Brady ct al., 1981, 1984; Black and Kurdyla. 1983; Tytell et al., 1984; Peng et al., 1985; McQuarric et al., 1986; Aletta and Greene, 1987; Oblinger et al., 1987). In addition, our control studies in nonelongating axons have analyzed $\mathrm{SCa}$ and $\mathrm{SCb}$ tubulin radioactivity as determined from both SDS=PAGE and 2=dimensional (2D) PAGE separations (McQuarrie et al., 1986; Oblinger et al., 1987); tubulin spots separated on 2D-PAGE contain over $95 \%$ of the radioactivity separable as "tubulin" bands on SIDS-PACF. (I. G. MCQuarrie, unpublished observations). Gel segments were solubilized in $0.5 \mathrm{ml} 30 \% \mathrm{H}_{2} \mathrm{O}_{2}$ at $60^{\circ} \mathrm{C}$ for $2 \mathrm{~d}$; Formula 963 scintillation cocktail or Ready-Solv HP/b (Beckman) was added, and radioactivity was measured in a liquid scintillation spectrometer (Beckman); a chemiluminescence monitor indicated that counts attributable to $\mathrm{H}_{2} \mathrm{O}_{2}$ were $1-3 \%$ of total cpm in fewer than $10 \%$ of vials, with the remaining $90+\%$ of vials having $<1 \%$ of total cpm attributable to chemiluminescence. Radioactivity levels were corrected for background, color quenching, isotopic decay, and efficiency; values were expressed as $d p m / 3 \mathrm{~mm} / \mu \mathrm{Ci}$; the amount of radioactivity injected was determined from aliquots taken then.

By crushing axons $27-30 \mathrm{~mm}$ from the spinal cord $7 \mathrm{~d}$ after pulselabeling newly synthesized proteins at the nerve cell body, and killing the animals $7-16 \mathrm{~d}$ after the crush, these experiments focus principally on the passage into sprouts of laheled proteins being transported at $2-$ $5 \mathrm{~mm} / \mathrm{d}$. This includes the $\mathrm{SCb}$ proteins, the front of which moves at $6 \mathrm{~mm} / \mathrm{d}$ while the peak moves at $3 \mathrm{~mm} / \mathrm{d}$ (McQuarrie et al., 1986). To determine transport rates from the movement of peaks of protein labeling, the least-squares method was employed to calculate the linear regression of distance on time. This allowed statistical tests to be used to determine whether a linedr function existed and provided the standard error of the rate (McQuarrie et al., 1977). The significance of differences in rate and initial delay were also determined. For measuring the amounts of labeling in $\mathrm{SCb}$ proteins, mean radioactivity values in consecutive $3 \mathrm{~mm}$ nerve segments were calculated at 7 and $14 \mathrm{~d}$ after crush ( $n=6$ at each interval). To evaluate nerves that were comparable in terms of specific activity, only 9 were chosen $(n=4$ at $7 \mathrm{~d}$ and 5 at 14 d), i.e., those having tubulin dpm values at the SCa peak no less than $30 \%$ of the value in the nerve with the greatest $\mathrm{SCa}$ tubulin radioactivity.

In a separate experiment, the maximum axonal outgrowth distances were determined by labeling the fast component of axonal transport with $\mathrm{L}-2,3-{ }^{3} \mathrm{H}$-proline (New England Nuclear): $50-100 \mu \mathrm{Ci}$ was injected into the motor columns $18-24 \mathrm{hr}$ before killing the rat on postcrush day $4,7,8$, or 11 . The weight and sex of the rat, isotope injection technique, and method of sciatic nerve removal were the same as described above, except that crushes were made at the junction of the L-4 and L5 spinal nerves to preserve the L-5 ventral root and spinal nerve and thereby double the numbers of labeled sprouts. Consecutive nerve segments $(2 \mathrm{~mm}$ ) were obtained from the gel slicer and placed in cold $\left(4^{\circ} \mathrm{C}\right) \mathrm{TCA}$ for $24 \mathrm{hr}$. After washing with cold $10 \% \mathrm{TCA}$, each nerve segment was dissolved in BTS-450 (Beckman) at $20-22^{\circ} \mathrm{C}$ for $24 \mathrm{hr}$. Ready-Solv NA (Beckman) nonaqueous scintillant was added and radioactivity measured as above. The distribution of protein radioactivity along the nerve was plotted on semilog graph paper; the intersection of 


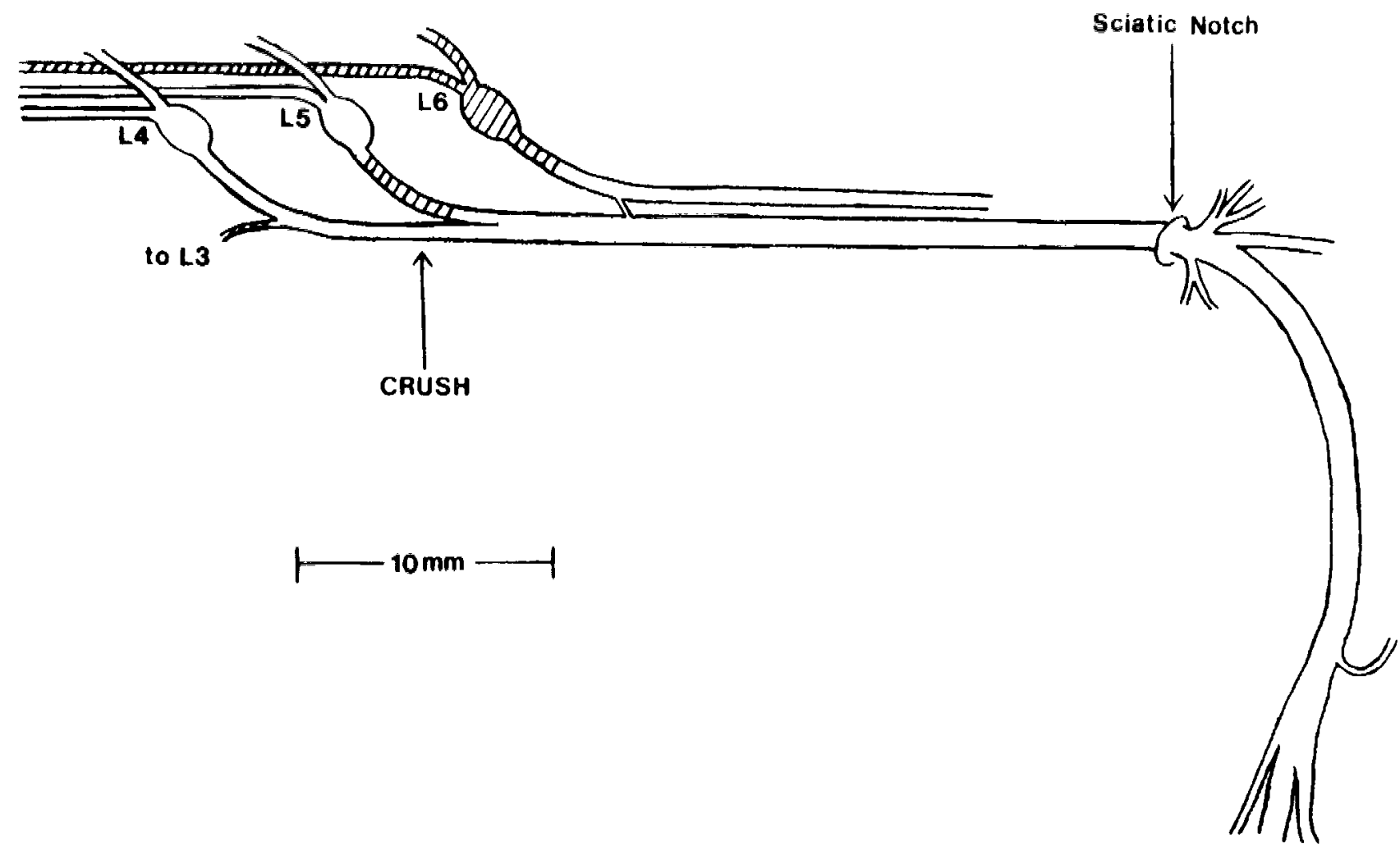

Figure 1. Sciatic nerve system of the rat. The motor neurons that project to the sciatic nerve are located in spinal cord segments L3-L6, which overlie the T13 and Ll vertebral bodies (McQuarrie, 1978). The L6 motor neurons largely project to the perineal and pudendal nerves, with only a small and inconstant branch reaching the sciatic nerve. The L4 spinal nerve may receive a communication from the L3 spinal nerve (which largely projects to the obturator nerve). Thus, the sciatic nerve is almost exclusively formed from motor neurons in the L4 and L5 spinal cord segments, by the junction of the L4 and L5 spinal nerves. To know exactly the distance from the spinal cord to the crush site, it is necessary to choose one of these for the crush and remove the other. We chose the L4 spinal nerve (contiguous with the L4 motor root), which is $1-2 \mathrm{~mm}$ longer than the L5 system. Crush lesions were made proximal to the junction of the L4 and L5 spinal nerves, at a point $27-30 \mathrm{~mm}$ from the spinal cord. To insure that all daughter axons would be sprouts from the L4 system, the L 5 spinal nerve was excised at the time of crush. In addition, the $\mathrm{L} 6$ system was removed by cutting the $\mathrm{L} 6$ spinal nerve and applying traction to the proximal stump. The L 3 communication was excised when present. The ablated parts of the sciatic nerve system are hatched in the illustration.

the steep line of declining radioactivity with background radioactivity in the degenerated nerve was taken to be the maximum extent of axonal outgrowth (Forman and Berenberg, 1978; McQuarrie, 1978; Tessler et al., 1980; Griffin et al., 1981). The regression function of distance on time was determined as above, yielding the maximum axonal outgrowth rate. Data from the slow transport experiments were similarly used to locate leading axons; this method represents a modification of the method placing axonal endings at the point where SC tubulin labeling reaches baseline (Black and Lasek, 1979). This modification places leading axonal endings in the most distal $3 \mathrm{~mm}$ nerve segment (located at or distal to the termination of $\mathrm{SCb}$ tubulin labeling) which has a peak of $\mathrm{SCb}$ labeling for both actin and the $58-67 \mathrm{kDa}$ group of proteins, which is enriched in MAPs (tau factors and chartins).

\section{Results}

\section{Elongation rate of regenerating daughter axons}

The site of the crush lesion is shown in Figure 1. The rate of elongation for the fastest regenerating axons was determined by using radiolabeled fast-transported proteins to locate those growth concs that had advanced farthest from the crush site (Griffin et al., 1976; Forman and Berenberg, 1978; McQuarrie, 1978). Figure 2 shows that the rate of maximal outgrowth (filled circles) was linear between 4 and $11 \mathrm{~d}$ after crush; the regression function of distance on time indicates an outgrowth rate of 4.4 $\mathrm{mm} / \mathrm{d}$. By extrapolating this line to zero distance, we estimate that the initial delay (before axons start to elongate distal to the crush) was $1.3 \mathrm{~d}$. These values for rate and initial delay are consistent with those obtained by others using the same method to study regenerating motor axons of the rat sciatic nerve: 3.5 $\mathrm{mm} / \mathrm{d}$ (Griffin et al., 1976); $4.4 \mathrm{~mm} / \mathrm{d}$ after a delay of $2.1 \mathrm{~d}$ (Forman and Berenberg, 1978); $3.6 \mathrm{~mm} / \mathrm{d}$ after a delay of 1.6 d (Bisby, 1985); and $3.9 \mathrm{~mm} / \mathrm{d}$ after a delay of $1.8 \mathrm{~d}$ (Bisby, 1979). Figure 2 also shows a determination of outgrowth rate by using the modified slow transport method of Black and Lasek (1979): $3.7 \mathrm{~mm} / \mathrm{d}$ with a delay of 1-2 $\mathrm{d}$. This regression function of distance on time is not significantly different from that determined by the fast transport method $(p<0.05)$.

\section{Qualitative analysis of cytoskeletal protein transport}

Figure $3 A$ is a fluorogram of radiolabeled proteins in axonal sprouts $8 \mathrm{~d}$ after crush ( $15 \mathrm{~d}$ after injection), an interval that permits all of the labeled $\mathrm{SCb}$ proteins to have passed from parent axons into daughter axons. Comparison of fluorograms of $\mathrm{SCb}$ in regenerating axons with those from normal axons at the same injection-kill interval (and at the same distance from the spinal cord) indicated that the pattern of labeled proteins in the daughter axons differred from that in normal axons. (For examples of fluorographs from normal axons at $14 \mathrm{~d}$ after injection, see McQuarrie et al., 1986, Fig. 7). Two bands at 60 and $65 \mathrm{kDa}$, which may represent labeling from MAPs called 
tau factors and chatins (Tytoil et a1, 1984 ; Peng et al., 1985 ; Aletta and Greene, 1987), were consistently present and woll resolved on fluorographs of gel segments throughout the length of daughter axons at $7-16 \mathrm{~d}$ after crush.

When a norve excision is used instead of a nerve crush, de= gencrating axons occupy the nerve instead of regenerating axons. Figure $3 B$ shows the pattern of $\mathrm{SCb}$ radioactivity remaining 8 $\mathrm{d}$ after nerve excision ( $15 \mathrm{~d}$ after isotope injection). By the time of nerve excision, the leading foot of $\mathrm{SCb}$ labeling had entered the distal nerve stump (which begins at the site of the crush lesion of the experimental group). Some of this label would remain with axonal debris and some would have been incorporated by phagocytic Schwann cells. This control study showed that more than half of the remaining protein radioactivity was in polypeptides unresolvable on a $4-17.5 \%$ gradient $S D S-\bar{P} A G \bar{E}$ gel, i.e., in polypeptides of less than approximately $12 \mathrm{kDa}$. [The $\mathrm{SCb}$ polypeptides of normal and regenerating daughter axons are almost entirely captured by a $4-17.5 \%$ gradient gel, since punches of total gel lanes recover more than $95 \%$ of the protein radioactivity placed in the well of the stacking gel (I. G. McQuarrie, unpublished observations).] The appearances of the fluorograms were similar to the $\mathrm{SCb}$ pattern in normal axons (McQuarrie et al., 1986) and did not include bands at 60 and $65 \mathrm{kDa}$ (Fig. 3A). Thus, a degree of reorganization occurs at the PDJ, such that newly formed axons become enriched in these proteins.

Although our experimental design emphasizes the transport of radiolabeled $\mathrm{SCb}$ proteins into daughter axons, some labeled $\mathrm{SCa}$ proteins also enter. The neurofilament triplet (NFT) proteins are the hallmark of $\mathrm{SCa}$, and the leading foot of labeling for the most abundant $(68 \mathrm{kDa})$ neurofilament protein was evident in the proximal segments of daughter axons at all intervals.

\section{Quantitative analysis of cytoskeletal protein transport}

To rigorously analyze the movement of slowly transported proteins from parent to daughter axons, the amounts of radioactivity in individual protein bands were measured. Tubulin is the most heavily labeled $\mathrm{SCb}$ protein and effectively illustrates the kinetics of radiolabeled cytomatrix proteins as these advance from parent to daughter axons. Figure 4 compares the distributions of tubulin radioactivity in regenerating axons 7 and 14 $\mathrm{d}$ after crush with distributions in nonelongating axons after the same labeling intervals.

In nonelongating axons, the peak of the labeled $\mathrm{SCb}$ wave (advancing at $3 \mathrm{~mm} / \mathrm{d}$ ) had passed the crush site $(27-30 \mathrm{~mm}$ from the spinal cord) by $14 \mathrm{~d}$ after labeling (Fig. $4 \mathrm{~A}$ ), and the crest of the labeled SCa wave was approaching that point by 21 d (Fig. 4B). However, at the time the crush lesion was made ( 7 $\mathrm{d}$ after labeling), only the leading foot of $\mathrm{SCb}$ (advancing at 4$6 \mathrm{~mm} / \mathrm{d}$ ) would have passed the crush site.

In elongating axons at $7 \mathrm{~d}$ after crush ( $14 \mathrm{~d}$ after labeling), the leading part of the $\mathrm{SCb}$ tubulin wave extended approximately $24 \mathrm{~mm}$ from the crush (Fig. $4 A$ ), and a week later it had advanced to approximately $51 \mathrm{~mm}$ (Fig. 4B). These distances coincide with the mean distance to the most distal small peaks of labeling for actin and the 58-67 kDa group (marked in Fig. 4 by " $c$ "). This information was used to estimate the position of the main body of axon terminals since the group of proteins at $58-67 \mathrm{kDa}$ showed a peak of labeling in every nerve at approximately the point where tubulin labeling fell to tissue background levels, and, in more than $85 \%$ of nerves, a peak of actin labeling was present in the same nerve segment. These distances,

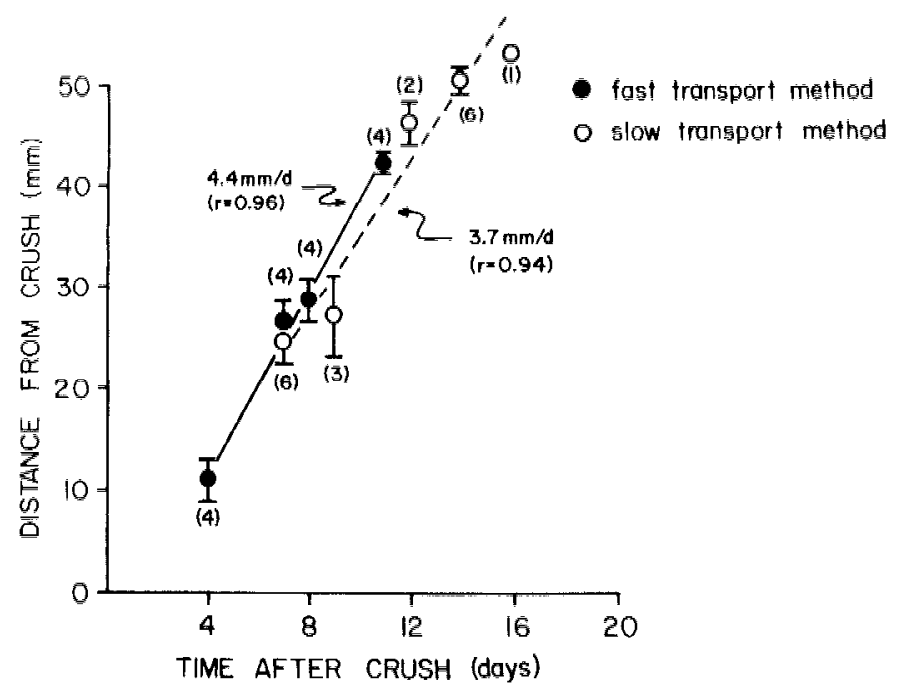

Figure 2. Axonal outgrowth rates. Two methods were used to measure rates: In the slow transport mcthod, outgrowth distances at $7-16 \mathrm{~d}$ after crush (14-23 d after labeling) were measured from the crush to the most distal peaks of labeling for actin and the 58-67 kDa group of proteins $(n=18)$. A peak of labeling for the $58-67 \mathrm{kDa}$ group was seen in every nerve; a peak of actin labeling was present in 16 of 18 nerves-in 13 of which it was in the same $3 \mathrm{~mm}$ nerve segment as the 58-67 kDa peak. When the 2 peaks were present but in adjacent segments $(n=3)$, the mean distance was used. In the 2 nerves lacking a peak for actin, the distance to the 58-67 $\mathrm{kDa}$ peak was used. When the regression function of these distances on time was plotted (open circles), the slope indicated an outgrowth rate of $3.7 \mathrm{~mm} / \mathrm{d}$. Extrapolation of this line to zero distance yielded an estimated initial delay of $1-2 \mathrm{~d}$. When outgrowth distances to the leading growth cones were measured directly (filled circles), by labeling fast-transported membranous proteins of the motor axons with ${ }^{3} \mathrm{H}$-proline in a separate experiment, the calculated regression of distance on time was $4.4 \mathrm{~mm} / \mathrm{d}$, with an estimated initial delay of $1.3 \mathrm{~d}$. Vertical lines denote SFM. Coefficients of correlation for each rate are given $(r)$. Taken together, the data suggest that the distal peaks of labeling for actin and the 58-67 kDa group denote the location of the main body of growth cones (McQuarrie, 1978; Griffin et al., 1981).

after different crush-kill intervals, are presented graphically in Figure 2 (open circles) and are compared with the distances measured by the fast transport method (filled circles). This method preferentially labels growth cones and locates the very small population of growth cones that advance most rapidly (Griffin et al., 1976, 1981; Forman and Berenberg, 1978; Tessler et al., 1980). Since most of the growth cones move more slowly, it is not surprising that the front of $\mathrm{SCb}$ proteins (marked by small peaks of labeling for the $58-67 \mathrm{kDa}$ group and actin at the termination of axonal tubulin labeling) moves slightly less rapidly.

In daughter axons at $7 \mathrm{~d}$ after crush, the tubulin waveform had 2 peaks located at mean distances of 9 and $15 \mathrm{~mm}$ from the crush site (marked "a" and "b" in Fig. 4A). Peak "a" is defined as the tubulin peak colocated with the crest of neurofilament protein labeling, and peak " $b$ " is defined as the tubulin peak colocated with the more distal crest of labeling for actin and calmodulin. These definitions correspond with those that we previously established for $\mathrm{SCa}$ and $\mathrm{SCb}$ in nonelongating motor axons (McQuarrie et al., 1986).

Figure $4 A$ shows that between 7 and $14 \mathrm{~d}$ after crush the waveform of radiolabeled tubulin had broadened in daughter axons. The "a" peak had also become more prominent and had 


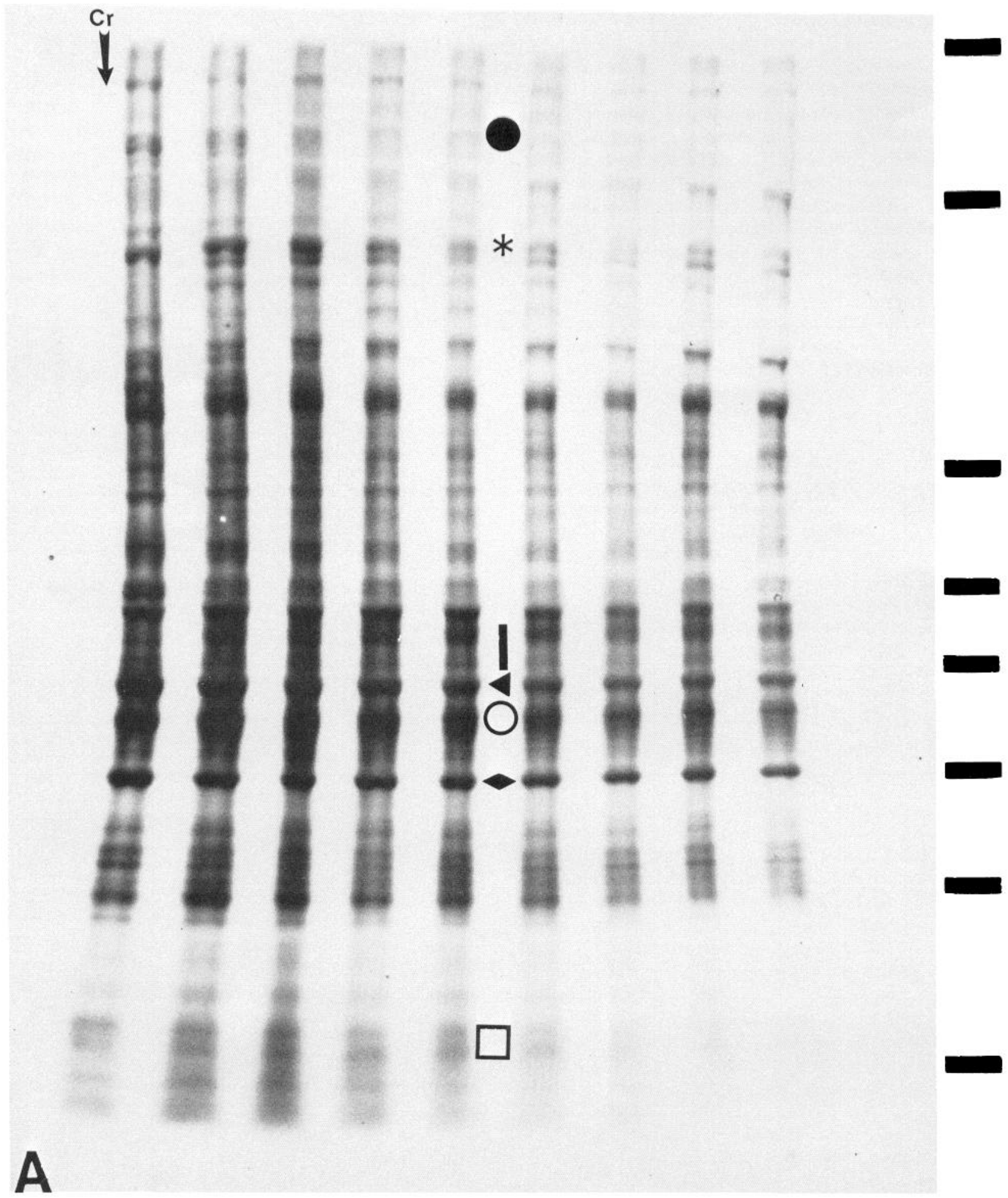

Figure 3. SDS-PAGE fluorograms showing radiolabeled polypeptides in consecutive $3 \mathrm{~mm}$ segments of the proximal sciatic nerve at $8 \mathrm{~d}$ after a lesion of the L4 and L5 spinal nerves and $15 \mathrm{~d}$ after isotope injection. In $A$, a crush lesion was made where the L4 and L5 spinal nerves unite to form the sciatic nerve $30 \mathrm{~mm}$ from the spinal cord $(C r)$; labeling is primarily in newly formed daughter axons. In $B$, the L4 and L5 spinal nerves were entirely excised, as were communications from L3 and L6 spinal nerves, to leave gaps of over 10 mm, which cannot be crossed by daughter axons within $8 \mathrm{~d}$ (McQuarrie and Grafstein, 1973); labeling is in degenerating motor axons and the phagocytic Schwann cells that digest these axons, beginning $30 \mathrm{~mm}$ from the spinal cord at the origin of the sciatic nerve $(E x)$. The acrylamide gradient for the runnings gels was $4-17.5 \%$, and the fluorograms were incubated at $-70^{\circ} \mathrm{C}$ for $3 \mathrm{wk}$. The amounts of isotope injected were nearly identical in each rat. However, a $50 \%$ larger aliquot ( $75 \mathrm{vs}$. $50 \mathrm{ml}$ ) was loaded in each lane of the gel in $B$ versus that in $A$ (to correct for the lower levels of radioactivity in degenerating vs. 
Ex

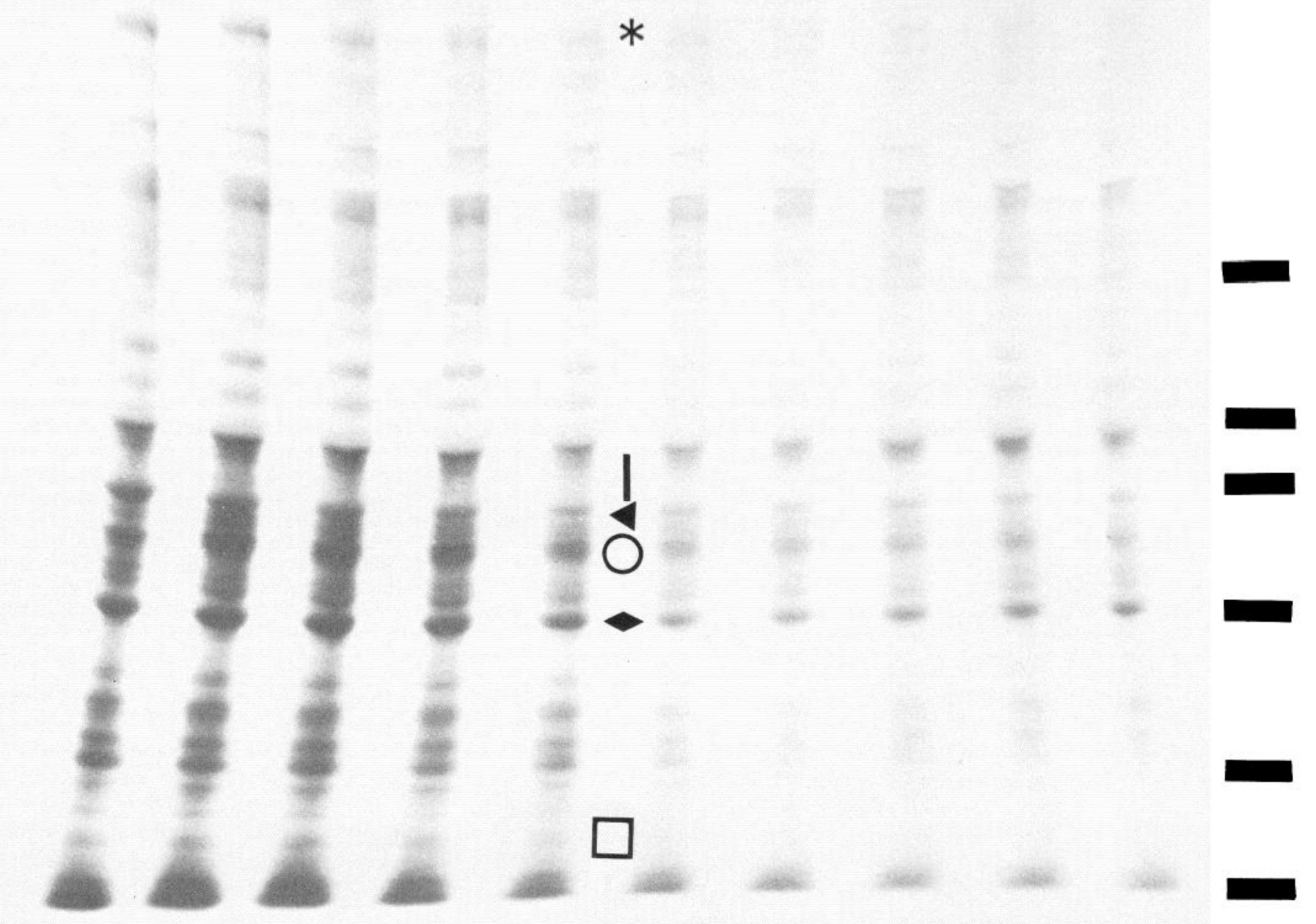

regenerating axons). Horizontal bars indicate positions of $M_{\mathrm{r}}$ standards running in the far-right gel lanes $(335,200,94,68,57,43,32$, and $14 \mathrm{kDa}$, reading top to bottom). Polypeptides that were removed (by using these fluorograms as templates) are indicated by symbols: spectrin, filled circle; 58-67 kDa group, vertical line; alpha tubulin, filled triangle; beta tubulin, open circle; actin, filled lozenge; and calmodulin, open square. The labeling patterns of both regenerating and degenerating nerves conform to the pattern for SCb in normal nerves, with 2 exceptions: (1) a prominently labeled polypeptide at $165 \mathrm{kDa}$ (asterisk) is only found in normal nerves near the injection site and is therefore a Schwann cell rather than neuronal protein; (2) the 58-67 kDa group shows prominent bands of labeling at 60 and $65 \mathrm{kDa}$ in regenerating nerves $(A)$, whereas normal nerves show only slight labeling cell at $60 \mathrm{kDa}$ (McQuarrie et al., 1986, Fig. 7) and degenerating nerves show no bands in this range $(B)$. 

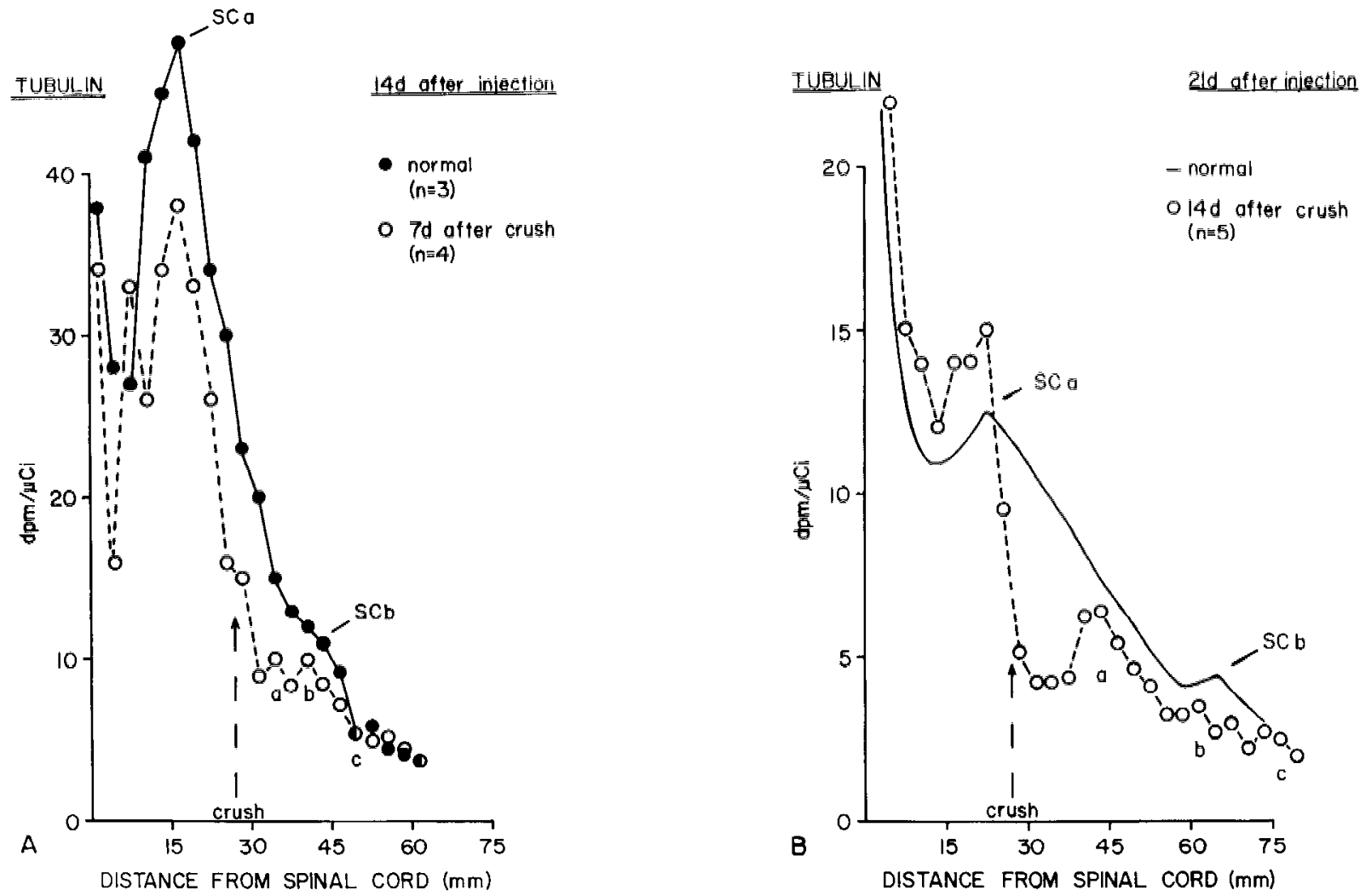

Figure 4. Axonal transport of labeled tubulin in nonelongating control versus regenerating sciatic motor axons at $14 \mathrm{~d}(A)$ and $21 \mathrm{~d}(B)$ after injection of isotope into the spinal cord. Tubulin transport data in nonelongating sciatic motor axons are replotted from a control study, performed concurrently with this experiment but published separately (McQuarrie et al., 1986). Actual values from 3 control nerves are used in $A$, whereas a free-hand line is drawn in $B$ that represents a composite of information from 18 control nerves with injection-kill intervals of 7-41 d that were used to measure the rate at which the peaks of labeling for $\mathrm{SCa}$ and $\mathrm{SCb}$ advance (cf. Figs. 9 and 11 in McQuarrie et al., 1986). In the controls (filled circles), $S \mathrm{Ca}$ is the peak of tubulin labeling that is associated with a peak of neurofilament labeling; $S C b$ is the peak of tubulin labeling that moves ahead of neurofilament protein labeling and is cotransported with peaks of labeling for actin and calmodulin (McQuarrie et al., 1986). In daughter axons, $a$ is the peak of tubulin labeling associated with the peak of neurofilament protein labeling (see Fig. 10); $b$ is the peak of tubulin labeling that moves ahead of neurofilament protein labeling and is cotransported with peaks of calmodulin and actin labeling (cf. Figs. 5 and 8 ); $c$ denotes distal colocated peaks of labeling for actin and the 58-67 kDa proteins (cf. Figs. 5 and 7), which may indicate the position of the main body of growth cones (cf. Fig. 2). These data indicate that the advance of the SCb peak through the parent axons is only halted for approximately $24 \mathrm{hr}$ before entering daughter axons: at both 14 and $21 \mathrm{~d}$ after injection (i.e., 7 and $14 \mathrm{~d}$ after crush, respectively), the $b$ peak is located only 3 $\mathrm{mm}$ proximal to the $S C b$ peak in nonelongating control nerves.

advanced a mean distance of $18 \mathrm{~mm}$. This peak was a distinctive feature of every regenerating nerve by the second week after crush, and there was no analogous peak at the same distance from the spinal cord in nonelongating axons after the same injection-kill intervals. The possibility that it represented a stationary " $b$ " peak (which is at a similar location $7 \mathrm{~d}$ after crush) was ruled out on 2 grounds: (1) the presence of labeled neurofilament proteins and (2) the clear progression demonstrated in nerves from animals killed at intervals other than 7 or $14 \mathrm{~d}$ after crush (i.e., at 9, 12, and 16 d). Thus, the "a" wave in daughter axons must be produced from radiolabeled proteins that were originally transported with $\mathrm{SCb}$ in parent axons and then transported with the "b" wave in daughter axons.

\section{Actin, spectrin, calmodulin, and the 58-67 kDa group}

The pattern of other labeled proteins (actin, spectrin, calmodulin, and the 58-67 $\mathrm{kDa}$ group) that are transported in the $\mathrm{SCb}$ wave (Figs. 5-8) was similar to that of tubulin (Figs. 4, 9). Like tubulin, these distributions of labeling had fronts in the growth cone region and peaks at the same positions as the "a" and " $b$ " tubulin peaks. Although the general shapes of these distributions were similar, the proportions of radioactivity moving with the growth cones (marked by the small "c" peak for actin and the 58-67 kDa group), the "a" peak, and the " $b$ " peak differed. Notably, actin, spectrin, and the 58-67 kDa group had higher "b" peaks than "a" peaks $7 \mathrm{~d}$ after crush (Figs. 5-7). In contrast, tubulin and calmodulin had the same amount of radioactivity in the "b" peak as in the "a" peak (Figs. 8, 9).

By $14 \mathrm{~d}$ after crush, only tubulin and actin had clear " $b$ " peaks in composite distributions (Figs. 5, 9), though these were evident in calmodulin, spectrin, and 58-67 $\mathrm{kDa}$ group distributions from individual nerves. While the " $b$ " peaks for several proteins occurred in the same $3 \mathrm{~mm}$ nerve segment in most nerves, the distance from the spinal cord to this segment differed from nerve to nerve. Since most of the " $b$ " labeling had become "a" labeling by $14 \mathrm{~d}$ after crush, the different distances and reduced specific activity meant that the composite of 5 nerve distributions for each protein had an unimpressive " $b$ " peak. Nonetheless, the growth cone region could be easily marked at $14 \mathrm{~d}$ after crush because of small peaks of cotransported labeling for actin, spectrin, and the 58-67 kDa group (peak " $c$ " in Figs. $5-7)$. 


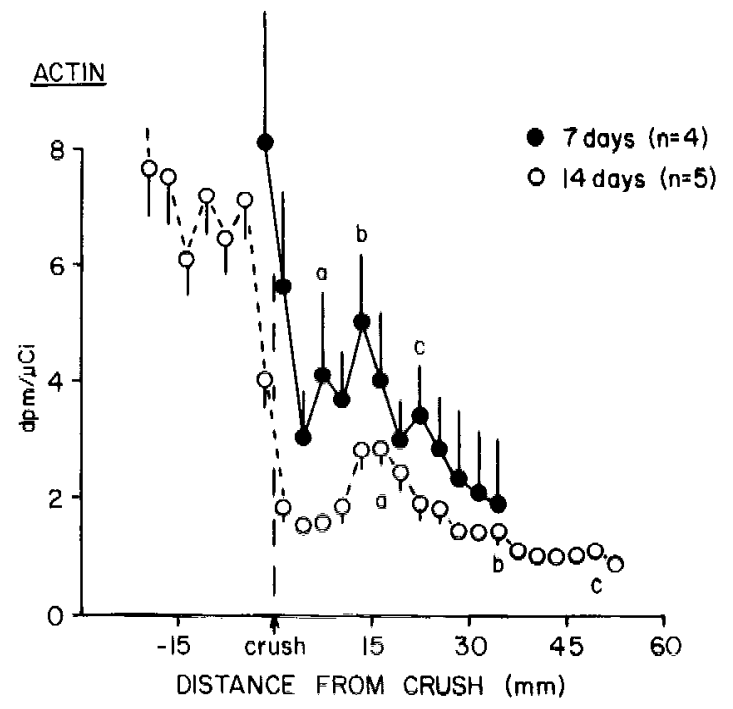

Fïgure 5. Distribution of actin radioactivity in motor axons. Nerves were removed at 7 and $14 \mathrm{~d}$ after crush. Microinjections of ${ }^{35} \mathrm{~S}$-methi= onine $(0.4-0.9 \mathrm{~m}(\mathrm{i})$ were made into the lumbar spinal cord $7 \mathrm{~d}$ prior to crush. Symbols $a, b$, and $c$ are defined in the legend to Figure 4 . The profile of radioactivity in daughter axons at $14 \mathrm{~d}$ after crush is similar to that seen in nonclongating control axons at $14 \mathrm{~d}$ after isotope injection (McQuarric et al., 1986). Vertical lines denote SEM

\section{Neurofilament proteins}

Although our experimental design highlights the transport of radiolabeled $\mathrm{SCb}$ proteins into daughter axons, Figure 10 shows that the leading foot of NFT labeling had entered daughter axons both 7 and $14 \mathrm{~d}$ after crush. The levels of labeling were low, as would be expected for injection-kill intervals that were insufficient to allow the crest of SCa labcling to reach the crush sitc. As in normal axons, the front of NFT labeling lagged some distance behind the front of tubulin labeling (McQuarrie et al., 1986).

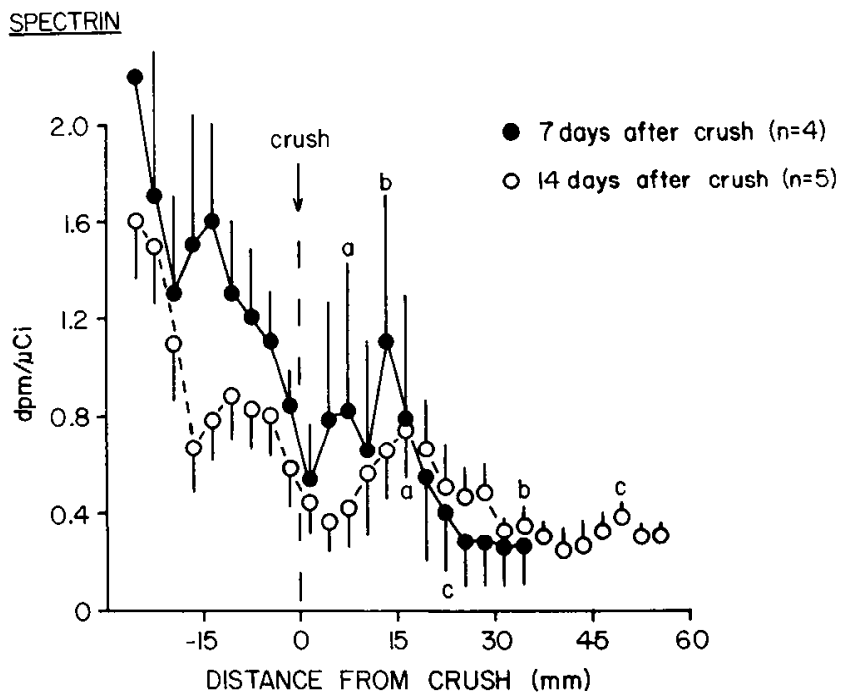

Figure 6. Distribution of spectrin radioactivity in motor axons at 7 and $14 \mathrm{~d}$ after nerve crush (same nerves and details as in Fig. 5).

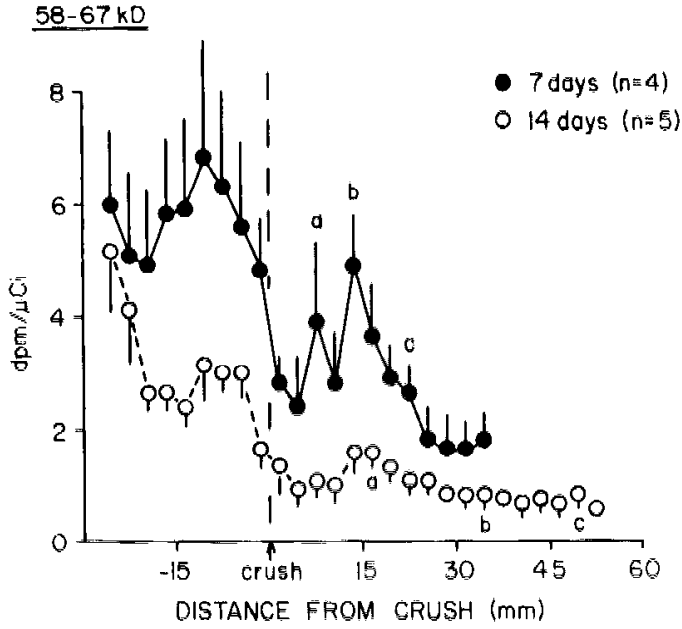

ligure 7. Distribution of radioactivity in the 58-67 kDa group of proteins in motor axons at 7 and $14 \mathrm{~d}$ after nerve crush (same nerves and details as in Fig. 5).

\section{Kinetics of " $a$ " and " $b$ " peaks correspond to those of SCa and $S C b$}

The positions of the "a" and " $b$ " peaks in daughter axons at 7 and $14 \mathrm{~d}$ suggest that these move anterogradely at the same respective rates as $\mathrm{SCa}$ and $\mathrm{SCb}$ peaks in nonelongating motor axons (McQuarrie et al., 1986). Figure 11 specifically compares the distances from the crush to the "a" peak in daughter axons with distances from the spinal cord to the SCa peak in nonelongating axons; the "b" and $\mathrm{SCb}$ peaks are similarly analyzed in Figure 12. For the "b" peak, the mean distances to the peaks for tubulin, actin, and calmodulin located ahead of the NFT peak were scored. In 8 of 18 nerves, the peaks of labeling for the 3 proteins were located in the same $3 \mathrm{~mm}$ nerve segment. Three nerves did not have a distinct calmodulin peak and 2 did not have a distinct tubulin peak; 5 nerves had colocation of 2 protein peaks, with the third being in the adjacent nerve seg-

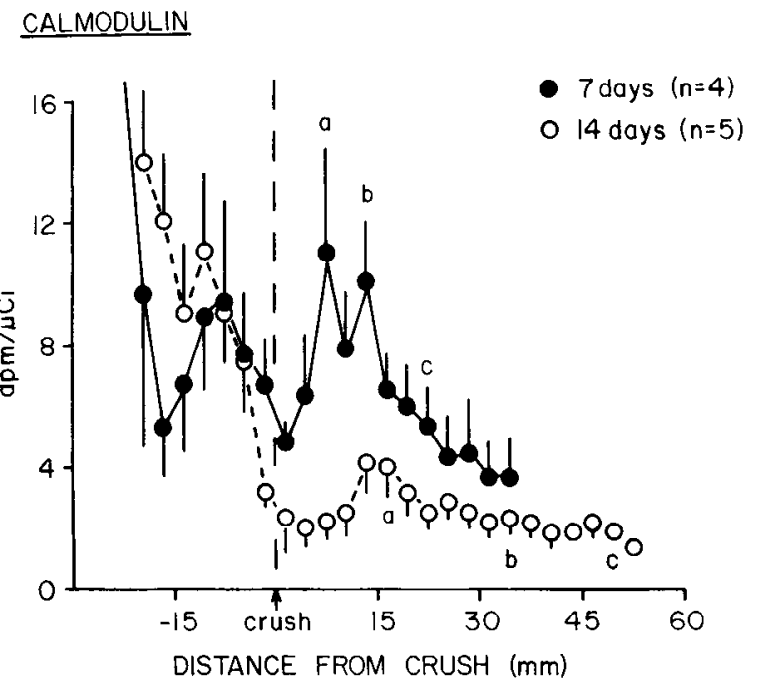

Figure 8. Distribution of calmodulin radioactivity in motor axons at 7 and $14 \mathrm{~d}$ after nerve crush (same nerves and details as in Fig. 5). 


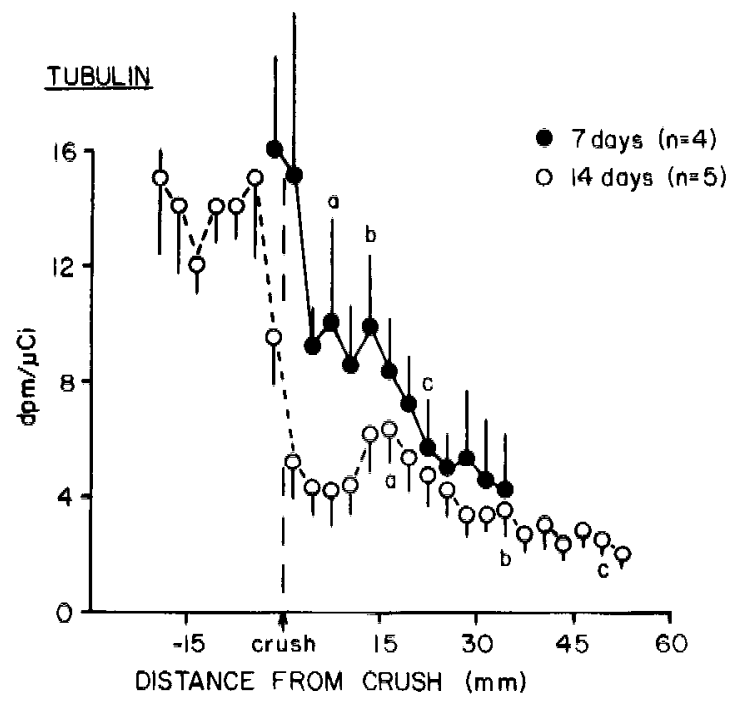

Figure 9. Distribution of uubulin radioactivity in motor axons at 7 and $14 \mathrm{~d}$ after nerve crush (same nerves and details as in Fig. 5).

ment. When the peaks were not all in the same segment, the average distance was calculated for the " $b$ " peak location, as had been done previously to locate the $\mathrm{SCb}$ peak in nonelongating axons (McQuarrie et al., 1986).

The rates for the tubulin " $a$ " peak in daughter axons, and the SCa tubulin peak in normal axons, were 1.25 and $1.32 \mathrm{~mm} / \mathrm{d}$, respectively (Fig. 11). For the " $b$ " peak in daughter axons and the $\mathrm{SCb}$ peak in normal axons, the rates were 2.90 and 3.08 $\mathrm{mm} / \mathrm{d}$, respectively (Fig. 12). The rates ("a" vs. SCa and "b" vs. $\mathrm{SCb}$ ), and the estimated initial delays, were statistically identical in both cases. This suggests that the " $a$ " and " $b$ " peaks in daughter axons correspond to the $\mathrm{SCa}$ and $\mathrm{SCb}$ peaks in normal axons.

\section{Discussion}

Kinetic studies of axonal transport demonstrate that the cytoskeletal elements of motor neurons are transported exclusively by slow transport at rates of $1-6 \mathrm{~mm} / \mathrm{d}$ in normal and regenerating axons (Hoffman and Lasek, 1975, 1980; McQuarrie et

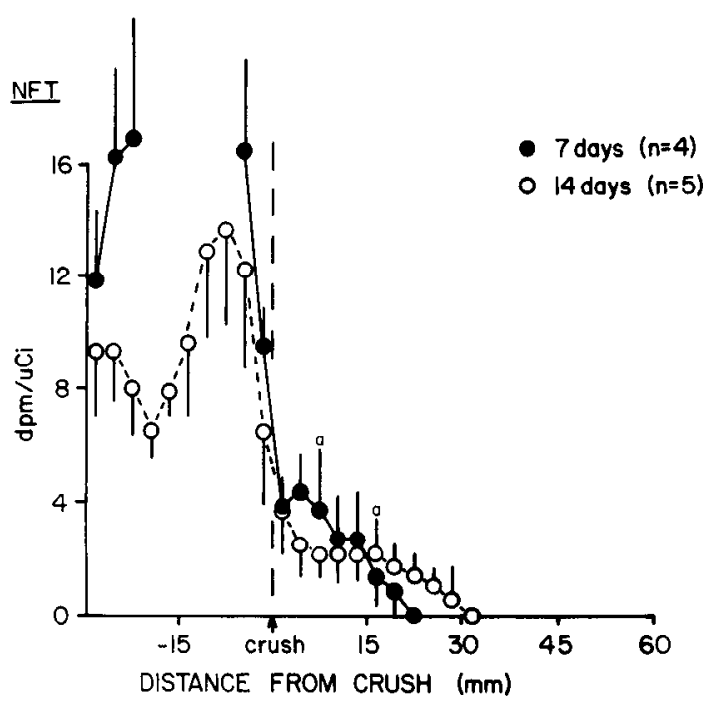

Figure 10. Distribution of NFT radioactivity in motor axons at 7 and $14 \mathrm{~d}$ after nerve crush (same nerves and details as in Fig. 5).
SCo peak

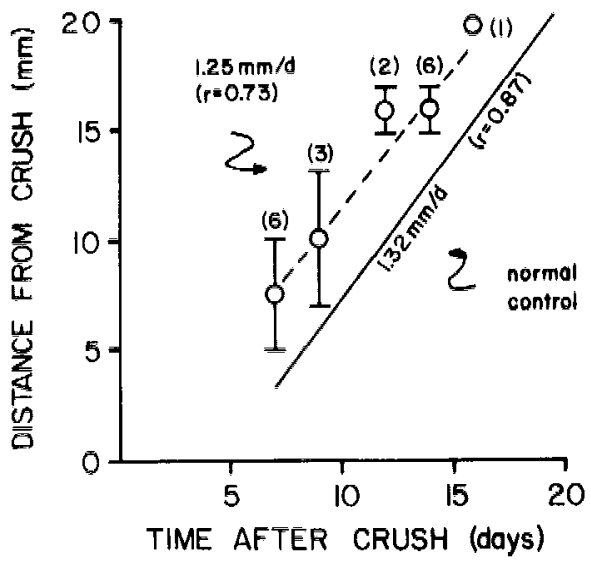

Figure 11. Mean distances to peak $a$ in daughter axons of 18 sciatic nerves (open circles). The L4 spinal nerves were crushed 1 weck after isotope injection. The calculated regression of distance on time for the a peak is $1.25 \mathrm{~mm} / \mathrm{d}$; extrapolation to \%ero distance suggests an initial delay of $l \mathrm{~d}$ before the $a$ peak entered daughter axon sprouts. Comparison is made to values obtained for entry of radiolabeled SCa tubulin peaks into ventral nerve roots of 14 nonelongating controls (Fig. 9 in McQuarric et al., 1986), which yielded a rate of $1.32 \mathrm{~mm} / \mathrm{d}$ after an estimated delay of $4-5 \mathrm{~d}$. There is no statistical difference between the 2 regression functions, either in terms of slope or displacement (initial delay). Vertical lines denote SEM.

al., 1986; Oblinger et al., 1987). Lasek and Hoffman (1976) have proposed that, if an axon is cut farther than $10 \mathrm{~mm}$ from the nerve cell body, the cytoskeleton of the daughter axon must

$\mathrm{SCb}$ peak

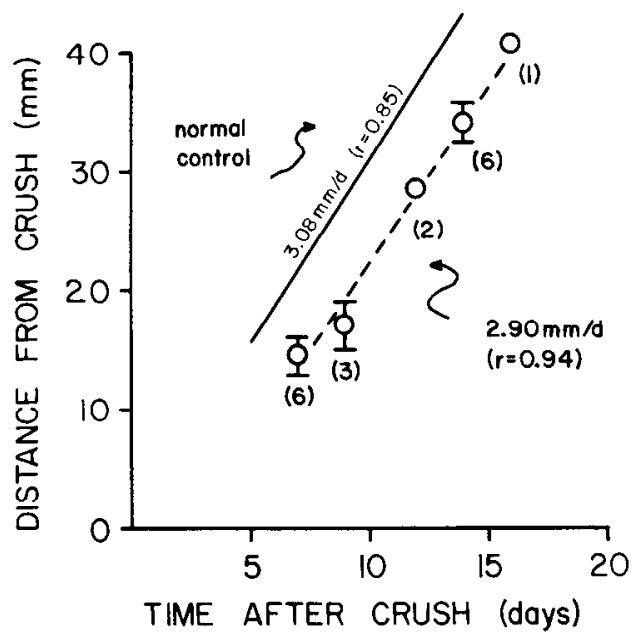

Figure 12. Mean distances to peak $b$ in daughter axons of 18 sciatic nerves (open circles). The L4 spinal nerves were crushed 1 week after injection. The calculated regression of distance on time for the $b$ peak is $2.90 \mathrm{~mm} / \mathrm{d}$; extrapolation to zero distance indicates an estimated initial delay of $2 \mathrm{~d}$ before the $b$ peak entered axon sprouts. Comparison is made to the regression function of distance on time for the movement of the $\mathrm{SCb}$ peak through nonelongating motor axons (Fig. 11 in McQuarrie et al., 1986), which indicates a rate of $3.08 \mathrm{~mm} / \mathrm{d}$ after an estimated delay of $0 \mathrm{~d}$. There is no statistical difference between the 2 regression functions, either in terms of slope or displacement (initial delay). Vertical lines denote SEM. 
arise from preexisting cytoskeletal elements that are already in transit within the parent axon when the lesion is madc. Specifically, they propose that the cytoskeletal elements in SCb contribute directly to the cytomatrix of the growth cone and the microtubules of the axon shaft. This "conservative" model of axonal growth has been further elaborated over the past decade (Lasek et al., 1981, 1983; McQuarrie, 1983, 1984, 1988). In keeping with the model, our study demonstrates that prelabeled cytoskeletal elements of $\mathrm{SCb}$ are readily transported into daughter axons. Furthermore, detailed kinetic analyses indicate that the basic characteristics of slow axonal transport have been preserved. Specifically, 2 waves termed " $a$ " and " $b$ " correspond to $\mathrm{SCa}$ and $\mathrm{SCb}$, respectively, as regards rate and overall composition. Thesc observations provide further evidence in support of the model.

\section{Cytoskeletal elements accumulate at the PDJ and are then recruited into daughter axons}

When an axon is cut (e.g., by a nerve crush), anterogradely transported cytoskeletal elements are prevented from advancing beyond the cut; these accumulate at the proximal stump of the cut axon. For example, Friede and Bischhausen (1980) have shown that at $72 \mathrm{hr}$ after axotomy the number of microtubules is 10 times greater in parent axon stumps than in the more proximal parent axon. The cytoskeletal elements that accumulate at the parent axon stump begin arriving soon after the axon is cut and continue to arrive as a function of transport rate and distance from the cut. In this way, slow transported elements that were moving through the parent axon at different average rates are concentrated at the PDJ; these cytoskeletal elements, which have arrived separately, then have the opportunity to enter the daughter axon together. Thus, a representative complcment of cytoskeletal elements of the parent axon can collect at the stump and become available for the fabrication of nascent daughter axons.

A simple analogy may be useful for understanding the behavior of cytoskeletal elements at the PDJ. Consider a population of racehorses running a steeplechase. They all start out together at the starting gate (analogous to the nerve cell body). As the horses run the course, they spread out, with the amount of spreading being a function of differences in speed and the distance travelled. At one point, they run into a corral (analogous to the parent axon stump), where they must stay for a period before resuming the race. When the corral is opened, the horses initially cluster together, as they did at the starting gate. They then continue the race in a group that again becomes spread out along the track.

\section{Reorganization of cytoskeletal elements at the PDJ}

In our experiment, motor axons were cut at the front of the prelabeled SCb wave, so that the radiolabeled $\mathrm{SCb}$ proteins were the principal source of radiolabeled proteins in daughter axons. Nonetheless, these radiolabeled elements became distributed in 2 discrete " $a$ " and " $b$ " waves that apparently correspond to SCa and $\mathrm{SCb}$, respectively. This indicates that an $\mathrm{SCa}$-like wave was generated in daughter axons from radiolabeled $\mathrm{SCb}$ cytoskeletal elements. Apparently, the kinetic behavior of cytoskeletal elements is not a rigid function of intrinsic chemistry.

These observations are consistent with the polymer sliding model of cytoskeletal transport (Lasek et al., 1983, 1984; Lasek, 1986; McQuarrie et al., 1986). In this model, the transport rate of cytoskeletal elements is a function of interactions with other cytoskeletal elements. For example, the faster-moving (SCblabeled) structures appear to be slowed by interactions with slower-moving (SCa-labeled) structures. In the present experiment, unlabeled SCa structures may accumulate with labeled SCb structures at the PDJ and then be transported with these into daughter axons. On this basis, we propose that radiolabeled SCb cytoskcletal elements may be slowed by interactions with unlabeled SCa elements that are transported into and through the daughter axons. It will be interesting to determine whether the rcverse occurs: Arc radiolabeled $\mathrm{SCa}$ clcments recruitcd into the " $b$ " wave of daughter axons?

\section{Parent-daughter radiolabeling method highlights transported components directly involved in axonal elongation}

Our kinetic analyses of individual cytoskeletal proteins suggest that some of these are selectively concentrated with the population of cyloskeletal elements that are transported into the daughter axon. For example, during the first week of axonal outgrowth the amounts of tubulin, calmodulin, and the 58-67 $\mathrm{kDa}$ proteins were greater in the " $\mathrm{b}$ " wave of daughter axons than in the $\mathrm{SCb}$ wave of intact axons. [The amounts of these radiolabeled proteins are also greater in the intact motor axons of young growing rats than in the intact motor axons of the adult rats used in this study (I. G. McQuarrie, unpublished observations).] Furthermore, the front of radiolabeled $58-67 \mathrm{kDa}$ proteins in daughter axons was coordinated with the position of the growth cones. This group of proteins includes some of the MAPs, i.e., tau factors and chartins (Black and Kurdyla, 1983; Tytell et al., 1984; Peng et al., 1985; Aletta and Greene, 1987).

Based on these observations, we propose that the assembly of the growth cone and the nascent daughter axon shaft from the cytoskeletal elements of the parent axon is a selective process. Apparently, some cytoskeletal elements of the parent axon have a particularly high affinity for the assembly conditions present in an elongating axon. These cytoskeletal elements are likely to be important for the mechanism of axonal elongation. Thus, detailed analyses of the proteins that are enriched in daughter axons may identify some of the biochemical processes that are essential for axonal elongation and, thus, for axonal regeneration.

\section{Conclusion}

In nonelongating motor axons, the mechanisms of cell motility that continually renew the cytoskeleton endow the axon with a constant potential for elongation. When a cut axon regenerates, the new growth cone is organized within a few hours from transported cytoskeletal and membranous elements that accumulate in the parent axon stump (McQuarric, 1985). As the growth cone advances and a daughter axon forms, transported cytoskeletal elements that would normally continue through this region of an uncut axon are recruited by the daughter axon. In time, the anterogradely transported structures of the parent axon pass smooothly into the daughter axon.

\section{References}

Aletta, J. M., and L. A. Greene (1987) Sequential phosphorylation of chartin microtubule-associated proteins is regulated by the presence of microtubules. J. Cell Biol. 105: 277-290.

Bisby, M. A. (1979) Differences in incorporation of axonally transported protein in regenerating motor and sensory axons. Exp. Neurol. 65: 680-684.

Bisby, M. A. (1985) Enhancement of the conditioning lesion effect in 
rat sciatic motor axons after superimposition of conditioning and test Iesionis, Exp. Neurol. 90:385-394.

Black, M. M,, and J. T. Kurdyla (1983) Microtubulé-associated prótcins in neurons. J. Cell Biol, 97: 1020-1028.

Black, M. M., and R. J. Lasek (1979) Slowing of the rate of axonal regeneration during growth and maturation. Exp. Neurol. $63: 108=$ 119.

Brady, $\mathbf{S}, \bar{T}_{i,} \mathbf{M}$. Tytell, $\mathrm{K}$. Heriot, and $\bar{R}$. J. Lasek (1981) Axonal transport of calmodulin: A physiologic approach to identification of long-term associations between proteins. J. Cell Biol : 89:607-614.

Brady, S. T., M. Tytell, and R. J. Lasek (1984) Axonal tubulin and axonal microtubules: Biochemical evidence for cold stability. J. Cell Biol. 99: 1716-1724.

Brown, M. C., and R. G. Butler (1976) Regeneration of afferent and cfforcnt fibres to muscle spindles after nerve injury in adult cats. J. Physiol. (Lond.) 260:253-266.

Forman, D. S., and R. A. Berenberg (1978) Regeneration of notor axons in the rat sciatic nerve studied by labeling with axonally transported radioactive proteins. Brain Res. 156: 213-225.

Friede, R. L., and R. Bischhausen (1980) The fine structure of stumps of transected nerve fibers in subserial sections. J. Neurol. Sci. 44:181203.

George, E. B., B. F. Schncidcr, R. J. Lasck, and M. J. Katz (1988) Axonal shortening and the mechanisms of axonal motility. Cell Motil. Cytoskelet. 9: 48-59.

Griffin, J. W., D. B. Drachman, and D. L. Price (1976) Fast axonal transport in motor nerve regeneration. J. Neurobiol. 7: 355-370.

Griffin, J. W., D. L. Price, D. B. Drachman, and J. Morris (1981) Incorporation of axonally transported glycoproteins into axolemma during nerve regeneration. J. Cell Biol. 88: 205-214.

Hoffman, P. N., and R. J. Lasek (1975) The slow component of axonal transport: Identification of major structural polypeptides of the axon and their generality among mammalian neurons. J. Cell Biol. 66: 351-366.

Hoffman, P. N., and R. J. Lasek (1980) Axonal transport of the cytoskeleton in regenerating motor neurons: Constancy and change. Brain Res. 202: 317-333.

Laemmli, U. K. (1970) Cleavage of structural proteins during the assembly of the head of bacteriophage T4. Nature 227: 680-685.

Lasek, R. J. (1986) Polymer sliding in axons. J. Cell Sci. (Suppl.) 5: 161-179.

Lasek, R. J., and P. N. Hoffman (1976) The neuronal cytoskeleton, axonal transport and axonal growth. In Cell Motility, Cold Spring Harbor Conference on Cell Proliferation, Vol. 3, R. Goldman, T. Pollard, and J. Rosenbaum, eds., pp. 1021-1049, Cold Spring Harbor Laboratory, New York.

Lasek, R. J., I. G. McQuarrie, and J. R. Wujek (1981) The central nervous system regeneration problem: Neuron and environment. In Posttraumatic Peripheral Nerve Regeneration, A. Gorio, H. Millesi, and S. Mingrino, eds., pp. 59-70, Raven, New York.

Lasck, R. J., I. G. McQuarrie, and S. T. Brady (1983) Transport of cytoskeletal and soluble proteins in neurons. In Biological Structures and Coupled Flows, A. Oplatka, and M. Balaban, eds., pp. 279-298, Academic, New York.

Lasek, R. J., J. A. Garner, and S. T. Brady (1984) Axonal transport of the cytoplasmic matrix. J. Cell Biol. 99: 212s-221s.

Laskey, R. A., and A. D. Mills (1975) Quantitative film detection of ${ }^{3} \mathrm{H}$ and ${ }^{14} \mathrm{C}$ in polyacrylamide gels by fluorography. Eur. J. Biochem. 56: $335-341$.

McQuarrie, I. G. (1978) The effect of a conditioning lesion on the regeneration of motor axons. Brain Res. 152: 597-602.

McQuarrie, I. G. (1981) Acceleration of axonal regeneration in rat somatic motoneurons by using a conditioning lesion. In Posttraumatic

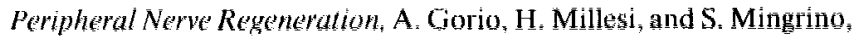
cds $;$ pp, 49-58, Raven, Now York.

McQuarrie, I, G. (1983) Role of the axonal cytoskeleton in the regenerating nervous systent. In Nerve, Organ, and Tissue Regeneration: Reseanch Perspectives, F. J. Seil, ed., pp. 51-88, Academic, New York.

McQuarrie, I. (1. (1984) Effect of a conditioning lesion on axonal transport during regeneration: The role of slow transport. In Axoinal Transpont in Neuronal Growth and Regeneration, J. S. Elam and P. Cancalon, eds., pp. 185=209, Plenum, Nèw York.

McQuarrie, $\bar{l}$. G. (1985) Eflect of a conditioning lesion on axonal sprout formation at nodes of Ranvier d. Comp. Neurol. 23:239249.

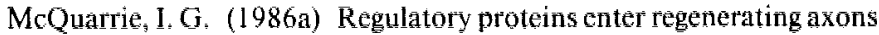
ahead of nicrotubules. Soc. Neurosci. Abstr. 12:513,

MeQuarrie, I. G. (1986b) Structural protein transport in elongating motor axons after sciatic norve crush. Effect of a conditioning lesion. Ncurochem. Pathol. 5: 153-164.

McQuarrie, I. G. (1988) Transport of cytoskeletal proteins into axonal sprouts during nerve regeneration. In The Current Status of Peripheral Nerve Regeneration, R. Stein and T. Gordon, eds., pp. 25-34, Liss, New York.

McQuarrie, I. G., and B. Grafstein (1973) Axon outgrowth enhanced by a previous nerve injury. Arch. Neurol. (Chic.) 29:53-55.

McQuarrie, I. G., and B. Grafstein (1982) Protein synthesis and axonal transport in goldfish retinal ganglion cells during regeneration accelerated by a conditioning lesion. Brain Res. 251: 25-37.

McQuarrie, I. G., B. Grafstein, and M. D. Gershon (1977) Axonal regeneration in the rat sciatic nerve: Effect of a conditioning lesion and of dbcAMP. Brain Res. 132: 443-453.

McQuarrie, I. G., M. King, and R. J. Lasek (1981) Transport of cytoskeletal proteins in newly-formed axons of regenerating rat sciatic nerve motoneurons. Soc. Neurosci. Abstr. 7: 38 .

McQuarrie, I. G., S. T. Brady, and R. J. Lasek (1986) Diversity in the axonal transport of structural proteins: Major differences between optic and spinal axons in the rat. J. Neurosci. 6: 1593-1605.

Miller, R. H., R. J. Lasek, and M. J. Katz (1987) Preferred microtubules for vesicle transport in lobster axons. Science 235: 220-222.

Oblinger, M. M., S. T. Brady, I. G. McQuarrie, and R. J. Lasek (1987) Cytotypic differences in the protein composition of the axonally transported cytoskeleton in mammalian neurons. J. Neurosci. 7: 453-462.

Peng, I., L. I. Binder, and M. M. Black (1985) Cultured neurons contain a variety of microtubule-associated proteins. Brain Res. 361: 200211

Takano, K. (1976) Absence of the gamma-spindle loop in the reinnervated hind leg muscles of the cat: "Alpha-muscle." Exp. Brain Res. 26: 343-354.

Tashiro, T., M. Kurokawa, and Y. Komiya (1984) Two populations of axonally transported tubulin differentiated by their interactions with neurofilaments. J. Neurochem. 43: 1220-1225.

Tessler, A., L. Autilio-Gambetti, and P. Gambetti (1980) Axonal growth during regeneration: A quantitative autoradiographic study. J. Cell Biol. 87: 197-203.

Tytell, M., S. T. Brady, and R. J. Lasek (1984) Axonal transport of a subclass of tau proteins: Evidence for the regional differentiation of microtubules in neurons. Proc. Natl. Acad. Sci. USA 81: 1570-1574.

Weiss, P. (1955) Nervous system. In Analysis of Development, $\mathrm{H}$. Willier, P. Weiss, and V. Hamburger, eds., pp. 346-401, Saunders, Philadelphia.

Weiss P., and H. B. Hiscoe (1948) Experiments on the mechanism of nerve growth. J. Exp. Zool. 107: 315-395.

Wujek, J. R., and R. J. Lasek (1983) Correlation of axonal regeneration and slow component $b$ in two branches of a single axon. $\mathrm{J}$. Neurosci. 3: 243-251. 